\title{
Impact of Information Communication Technology on Education-Kenya
}

\section{Kagwiria Josephine Kirimi}

\author{
School of Education, Mount Kenya University, Kenya \\ Email:joskirimi@yahoo.com
}

\section{Doi:10.5901/jesr.2014.v4n1p435}

\begin{abstract}
Kenya has made remarkable progress putting in place an ICT policy framework and implementation strategy, complete with measurable outcomes and time frames. The process has had the benefit of sound advice from officials and stakeholders and, perhaps more importantly, strong leadership from the office of the permanent Secretary of the Ministry of Education. However, universal implementation is challenging given the lack of resources, national ICT infrastructure, and even electrical supplyparticularly in the rural areas. As technology is bound to rule our present and future, it is good to obtain know-how of the technological reforms at the earliest. Children learn faster and can adapt to changes relatively easily. If they are trained during their school years, they have a high chance of becoming experts in technology. Computers can give lovelier explanations to various subjects. The internet is an ocean of information which can be harnessed for the rendition of information in school. The inclusion of technology in the learning process makes learning an enjoyable activity, thus inviting greater interest from the learners. The administration processes, the official procedures of the school can be simplified by the means of technology. School records, the information about all the students and the teachers and other school employees can efficiently be maintained by means of the advanced technology. Thus we see that technology not only benefits the school students but also eases the office work. It makes possible a more effective way of storage and distribution of information. The realization of the importance of technology in schools and its successful implementation is a necessity. The introduction of technology in schools is the means to bridge the long distance between the present and the future.
\end{abstract}

Keywords: Education, technology, information, performance

\section{Introduction}

Technology is the need of the day. The technology advancements have made society take a leap towards success. Every technological reform is a small step towards advancement. Every new invention in technology is a step towards progress of mankind. Centuries ago, hardly anyone would have even dreamt of working on a computer. Generations of yester years would have hardly imagined being able to communicate with people on the other side of the globe. But there were some intelligent minds that dared to dream of such revolutionary discoveries and they made the impossible possible. Ours as well as our future generations are lucky to be able to witness the technological reforms. We are fortunate enough to lead a life of luxury and comfort, since ours are the times of technology, why not let the technological reform spread far and wide? Why not make the masses aware of the new technology? Why not equip the entire society with the knowledge of the new inventions in technology? The need to introduce technology at an early age in life, illustrates the importance of technology in schools.

Information and communication technology (ICT) is universally acknowledged as an important catalyst for social transformation and national progress. However, disparities in the levels of ICT readiness and use could translate into disparities in level of productivities and hence could influence a country's rate of economic growth. Understanding and leveraging ICT is therefore critical for countries striving for continued social and economic progress.

Improved secondary education is fundamental to the creation of effective human capital in any country. In an effort to eradicate poverty and ensure sustainable socio-economic development in Africa, the newly formed New Partnership for Africa`s Development (NEPAD) recognizes that a key issue is the development of human resources in the region. The crisis facing human resource development in Africa is clearly manifested in the secondary education sub-sector in forms of limited access and poor quality.

The World Bank (2005) describes secondary education as the crucial link between primary schooling, tertiary education, and the labour market. As the World Bank (2005) notes, the task confronting education policymakers in Africa is to transform secondary education institutions and current schooling practices to align them with the fast growing demands of globalization and the technology driven world. Thus the main focus of the education policy process in Africa 
is to address the twin challenges of increasing access to, and improving quality and relevance of secondary education for all young people in the region. This underscores the imperative to transform teaching and learning in primary and secondary schools in African countries. This is what the NEPAD e-school projects wants to accomplish with a new paradigm of educational curriculum delivery. This new and integrated strategy for socio-economic development in Africa paves way for the improvement in quality and expansion of access to public education in the region.

The NEPAD e-mail projects aims to equip secondary schools (and later primary schools) in Africa with information and communication technologies (ICTs) to enable educational transformation to meet the demands of the $21^{\text {st }}$ century. In the long-run, modern communication technologies are expected to be widely deployed for teaching and learning in primary and secondary schools across Africa. This broad-based technology-enhanced education will be implemented through a collaborative partnership system in African countries.

Many countries have acknowledged the fact that investment in ICTs is an investment in human capital development which are essential in order to meet the demands for new meanings of "School" and "learning", within the larger process of education reform. Considering the level of poverty is Africa, it is ideal to ask whether it is reasonable to invest huge amount of money in ICTs for the educational development, instead of using such resources to meet other needs of the secondary education system in the region. Such resources one may argue, can be used to construct more classrooms, provide updated textbooks for students, or better still used to provide electricity and good access to roads to secondary schools in rural and remote communities in Africa.Luis Osin (1998), argues that the only way to reach a longterm solution for the economic problems of the population is to raise the educational level, particularly for the low socioeconomic groups.

The objectives of ICT in education cannot be realized without basic infrastructure and educational resources. Therefore integrating ICT in secondary education cannot be pursued in isolation rather it should be seen as an integral part of the overall strategy for knowledge creation and the improvement of educational system in Africa. Technology has found its way into every aspect of our culture today. It is in medicine, social work and in our education systems. Teachers are continually being encouraged to take technology classes so that their students can benefit from their knowledge. In education, technology plays a great role in the classroom, in assistive technology products, and software that is brought about into the school. Technology is embedded in our culture and we are immersed and dependent on it.

Technology changes so rapidly and has such pervasive impact that it is actually determining our culture. Children and adolescents are prime users and beneficiaries. Administrators and educators need to keep pace with life outside the classroom in order to integrate and access the wonderful learning opportunities the internet, ipods, cell phones, podcasting, and even social networking sites and video game play offer. Today's youth spend half their leisure time in front of screens- it is a huge part of their life. Teaching in a didactic/lecture format no longer works, and it is not utilizing the power of technological advances. Teachers need to invite students to learn by using what they know best-tech gadgets therefore the need to introduce ICT in secondary schools.

\section{Inception of ICT in Kenya}

Kenya promulgated a National ICT policy in January 2006 that aims to improve the livelihoods of Kenyans by ensuring the availability of accessible, efficient, reliable and affordable ICT services. The government is therefore out to encourage the use of ICT in schools, colleges, Universities and other educational institutions in the country so as to improve the quality of teaching and learning. The related strategies, under the heading E-learning, are to:

Promote the development of e-learning resources. Facilitate public-private partnerships to mobilize resources in order to support e-learning initiatives.

Promote the development of an integrated e-learning curriculum to support ICT in education.

Promote distance education and virtual institutions, particularly in higher education and training.

Promote the establishment of a national ICT centre of excellence. Provide affordable infrastructure to facilitate dissemination of knowledge and skill through e-learning platforms

Promote the development of content to address the educational needs of primary, secondary, and tertiary institutions. Create awareness of the opportunities offered by ICT as an educational tool to the education sector.

Facilitate sharing of e-learning resources between institutions. Exploit e-learning opportunities to offer Kenyan education progrmmes for export Integrate e-learning resources with other existing resources. The country needs to introduce ICT in secondary schools to enhance learning and teaching which in return will benefit the learner and the economy of the country as well. Therefore this justifies the need to carry out on ICT in secondary schools to know the extent it has been implemented, its impact and the challenges face by the implementers. 


\section{Introduction of ICT in Management of Schools}

The Ministry of Education developed a Kenya Education Sector Support Program (KESSP) in 2005 that featured ICT as one of the priority areas with the aim of mainstreaming ICTs into the teaching and learning process. The National ICT Policy embedded this intent as a national priority and provided the impetus for the ministry to develop its sector policy on ICT in Education.

The ministry moved quickly and, in June 2006, introduced the National ICT strategy for Education and Training. The Ministry of Education was given the mandate to lead the monitoring and evaluation of the strategy's implementation, guided by overall government policies on education and ICT, specific education strategic documents for implementing its mandate, and global goals such as Education for All (EFA) and the Millennium Development Goals (MDGs). This mandate is carried out through a ministerial ICT committee that meets monthly and reports quarterly on progress and it is chaired by the Permanent Secretary and supported by the ministry`s ICT unit. The ICT policy for the education sector consists of the following components, each with its own statement of strategic objectives and expected outcomes:

- ICT in education policy

- Digital equipment

- Connectivity and network infrastructure

- Access and equity

- Technical support and maintenance

- Harnessing emerging technologies

- Digital content

- Integration of ICT in education

- Training (capacity-building and professional development)

- Research and development

- ICT in education can be broadly categorized in the following ways as:

- ICT as a subject (computer studies)

- ICT as a tool to support traditional subjects (computer-based learning, presentation, research)

- ICT as an administrative tool (education management information systems/EMIS)

\section{Secondary Schools and ICT}

Improved secondary education is fundamental to the creation of effective human capital in any country. Secondary school education system is the most strategic education sector and unfortunately the least developed and the least available in Africa. With the vision of changing teaching and learning paradigms in Africa, the e-schools initiative aims to tackle the problems of secondary education in the region through the application of information and communication technologies (ICTs). However, a successful exploitation of the potential of ICTs for the enhancement of secondary education depends more on pedagogical and inter-organisational strategies than ICT issues.

The rationale for integrating ICTs in education was substantiated in a report issued by the organization for Economic Co-operation and Development (Organisation for Economic Co-operation and Development (OECD), 2001) on the impact of ICT in schools. In addition, the report identified other rationale for integrating ICT in education and these include: Economic rationale which has a focus on the perceived needs of the economy and the requirements to meet the skill and learning needs of the information economy; Social rationale which focuses on facility with ICT becoming a prerequisite for participation in society and employment, so that ICT competence is seen as an essential life skill and a basis for maintaining employability throughout life; Pedagogical rationale which concentrates on the role of ICT in teaching and learning and the ways in which ICT can increase the breadth and richness of learning, foster motivation for learning, and support the development of higher-order thinking skills (OECD, 2001).

Generally, the expected advantages of integrating ICTs in secondary education in Africa are: effective curriculum delivery by teachers as facilitators; improved learning by raising curiosity; technological literacy among students; expanding educational access to remote communities that were formerly deprived of education due to distance, culture, economic needs or gender disparities; and to prepare students for the world work.

The recent boom in the growth and development of the telecommunication sector in many countries around the world, such as internet connectivity, the use of and the diffusion of mobile phone technology are associated with the involvement of the private sector. The liberalization of the telecommunication sector and the participation of the sector 
will ensure healthy competition, which will improve the quality of service provision and of course reduce the cost of telephone lines and internet hosts in African countries. Fortunately, many countries in sub-saharan Africa have begun the process of liberalizing and privatizing their telecommunications sectors (Mutula, 2003). It is expected that this will not only improve teledensity in Africa, but also enhance the application of ICTs for the improvement of secondary education in the region.

The Ministry`s policy framework indicates that there are a number of challenges concerning access to and use of ICT in Kenya, including high levels of poverty, limited rural electrification, and frequent power disruptions. Most secondary schools have some computer equipment; however, this could consist of one computer in the office of school head. Very few secondary schools have sufficient ICT tools for teachers and students. Even in schools that computers the student -computer ratio is 150:1. Most schools that with ICT infrastructure have acquired it through initiatives supported by parents, the government, NGOs, or other development agencies and the private sector, including the NEPAD e-schools programme.

The core problem is that Kenya lacks adequate connectivity and network infrastructure. Although a small number of schools have direct access to high-speed connectivity through an internet service provider, generally there is limited penetration of the national physical telecommunication infrastructure into rural and low-income areas. Consequently, there is limited access to dedicated phone lines and high-speed connectivity for e-mail and the internet. Even where access to high-speed connectivity is possible, high costs remain a barrier to access. As well, very few schools can afford to use VSAT technology. Roughly $10 \%$ of secondary schools with computers are able to share teaching resources via a LAN. As a solution to these access problems, the ministry hopes to leverage the e-government initiative of networking public institutions countrywide to facilitate connectivity for the educational sector.

Infrastructure can also be organizational in nature. There are three organizations of critical importance in the context of ICT development in Kenyan schools. ICT to schools and communities and acts with its members as a cocoordinating body for sharing information about priorities and developments.

\section{Importance of ICT in Schools}

Kenya has placed considerable emphasis on the importance of ICT in its Education Sector Support Programme as evidenced in the recent promulgation of the National ICT strategy for Education and training. The Ministry of Education has taken the steps to support the implementation of the strategy either by direct action or through the various institutions and agencies with which it works. In addition, there are many other organizations not involved directly with the Ministry of Education that continue to be active in implementing and supporting projects involving ICT in education.

\section{Implementation of ICT in Education}

The core factors that influence the adoption and diffusion of ICTs in education have been identified in many studies and project reports such as the UNESCO meta-survey on the use of Technologies Asia and the pacific and, in the context of East Africa, by IDRC in its thorough analysis of ICT policy-making in the region. Two other studies that have discussed some of these factors in the higher education sector are those carried out by the United Nations National University and by the African Virtual University. What emerges from these analysis is that the factors are essentially the same in both developed and developing economies, although they differ in terms of importance depending on which side of the "digital divide" they are viewed from. What differentiates the rate of adoption and diffusion is not a difference in the factors at play, but rather the degree to which they have been developed or are present in a given country.

This Table provides a summary of the current stage of ICT development in Kenya in terms of enabling or constraining features in the education system

\begin{tabular}{|c|l|c|}
\hline Factors & \multicolumn{1}{|c|}{ Enabling features } & Constraining features \\
\hline $\begin{array}{c}\text { Policy framework } \\
\text { and } \\
\text { implementation } \\
\text { plans }\end{array}$ & $\begin{array}{l}\text { Sophisticated ICT in education strategy and } \\
\text { implementation } \\
\text { Embedded in national ICT policy developed through } \\
\text { consultative process with stakeholders. The plan has } \\
\text { costing estimates, time lines with measurable outcomes }\end{array}$ & \\
\hline $\begin{array}{c}\text { Advocacy } \\
\text { leadership }\end{array}$ & $\begin{array}{l}\text { Minister for education and permanent secretary } \\
\text { demonstrate a very strong commitment to the importance } \\
\text { of ICT in education }\end{array}$ & \\
\hline
\end{tabular}




\begin{tabular}{|c|c|c|}
\hline Gender equity & $\begin{array}{l}\text { Equity of access is stressed in policy and implementation } \\
\text { documents. Usage in schools is said to be equitable }\end{array}$ & $\begin{array}{l}\text { Female participation rates are equal at primary } \\
\text { level, decline in secondary level and drop } \\
\text { significantly at tertiary levels }\end{array}$ \\
\hline $\begin{array}{l}\text { Infrastructure and } \\
\text { access }\end{array}$ & & $\begin{array}{l}\text { Lack of national infrastructure seriously } \\
\text { constrains the use of ICTs in schools, } \\
\text { particularly in rural areas. Lack of reliable and } \\
\text { affordable access to the internet is a serious } \\
\text { constraint. Lack of bandwidth access seriously } \\
\text { constrains ICT }\end{array}$ \\
\hline $\begin{array}{l}\text { Collaborating } \\
\text { mechanisms }\end{array}$ & $\begin{array}{l}\text { Kenya is well served. Kenya ICT Trust Fund is a model to } \\
\text { be copied in terms of a PPP to garner resources for ICT } \\
\text { in education.KEI facilitates collaboration and in the NGO } \\
\text { sector, the NICE umbrella provides a mechanism for } \\
\text { coordination of differing and effective initiatives. }\end{array}$ & \\
\hline $\begin{array}{l}\text { Human resource } \\
\text { capacity }\end{array}$ & $\begin{array}{l}\text { Remedial initiatives are being taken but will take time to } \\
\text { develop. The strategic plan places a great deal of } \\
\text { emphasis on the need for training. }\end{array}$ & $\begin{array}{l}\text { An ICT plan of the ministry recognizes a current } \\
\text { deficit in terms of HR capacity to lead and } \\
\text { support the implementation of the plan. Skill } \\
\text { sets in the school are too low. Need for training } \\
\text { teachers and a school manager are widely } \\
\text { recognized and is being addressed, the } \\
\text { challenge is huge and will take time. This } \\
\text { constrain is more pronounced at the primary } \\
\text { level. }\end{array}$ \\
\hline Fiscal resources & $\begin{array}{l}\text { Existence of the strategic framework appears to be } \\
\text { bringing forth both donors and the private sector to } \\
\text { participate in the ICT Trust Foundation }\end{array}$ & \\
\hline Learner content & $\begin{array}{l}\text { Digital content development is underway for the school } \\
\text { curricula and in a collaborative manner, among some of } \\
\text { the Universities (Avoir Project) }\end{array}$ & $\begin{array}{l}\text { Currently there is not much available and there } \\
\text { is a lack of access to that which is available. } \\
\text { There is need to develop content in local } \\
\text { language as well as English }\end{array}$ \\
\hline $\begin{array}{l}\text { Procurement } \\
\text { regulations }\end{array}$ & & $\begin{array}{l}\text { Duties and taxes currently levied on ICT } \\
\text { products make them too expensive }\end{array}$ \\
\hline Attitudes & $\begin{array}{l}\text { There is a strong belief that the incorporation of ICT is } \\
\text { essential at all education levels. This shared from the } \\
\text { political to the student level. }\end{array}$ & $\begin{array}{l}\text { There is a perception that distanceeducation is } \\
\text { "second best" }\end{array}$ \\
\hline Sustainability & $\begin{array}{l}\text { The ministry recognizes that the adoption of ICT needs to } \\
\text { be based on an understanding of the total cost of } \\
\text { ownership. Strategies for sustainability are being } \\
\text { developed at local levels through community involvement } \\
\text { and service provision }\end{array}$ & $\begin{array}{l}\text { The experience of projects failing once project } \\
\text { funding is over is common giving rise to some } \\
\text { cynicism }\end{array}$ \\
\hline
\end{tabular}

Although valuable lessons may be learned from best practices around the world, there is no one formula for determining the optimal level of ICT integration in the educational system. Significant challenges that policy makers and planners, educators, education administrators, and other stakeholders need to consider include educational policy and planning, infrastructure, language and content, capacity-building and financing.

Attempts to enhance and reform education through ICTs require clear and specific Objectives, guidelines and time-bound targets, the mobilization of required resources, and the political commitment at all levels to see the imitative through. The essential elements of planning for ICT are:

A rigorous analysis of the present state of educational system: ICT-based interventions must take into account current institutional practices and arrangements. Specifically, drivers and barriers to ICT use need to be identified, including those related to curriculum and pedagogy, infrastructure, capacity-building, language and content, and financing. The specification of educational goals at different education and training levels as well as the different modalities of use of ICTs that can best be employed in pursuit of these goals. This requires of the policymaker an understanding of the potentials of different ICTs when applied in different contexts for different purposes, and an awareness of priority education needs and financial and human resource capacity and constraints within the country, as well as best practices around the world and how these practices can be adapted for specific country requirements.

The identification of stakeholders and the harmonizing of efforts across different interest group: 
The piloting of the chosen ICT-based model. Even the best designed models or those that have already been proven to work in other in other contexts need to be tested on a small scale. Such pilots are essential to identify, and correct, potential glitches in instructional design, implementability, effectiveness, and the like. The specification of existing sources of financing and the development of strategies for generating financial resources to support ICT use over the long-term.

\section{Infrastructure Related Challenges in ICT Enhanced Education}

A country's educational technology infrastructure sits on top of the national telecommunications and information infrastructure. Before any ICT-based programme is launched, policymakers and planners must carefully consider the following: Are appropriate rooms or buildings available to house the technology? Availability of electricity and telephony. Limited access to electricity and phone lines, few people in Kenya have a computer at home. Access to computers in schools, communities, households and affordable internet service.

\section{Challenges With Respect To Capacity-Building}

Various competencies must be developed throughout the educational system for ICT integration to be successful.

\subsection{Teachers:}

Teacher professional development should have five foci:

1. Skills with particular applications;

2. Integration into existing curricula

3. Curricula changes related to the use of IT (including changes in instructional design)

4. Changes in teacher role

5. Underpinning educational theories.

Ideally these should be addressed in pre-service teacher training and built on and enhanced in-service. In some countries, like Singapore, Malaysia, and the United Kingdom, teaching accreditation requirements include training in ICT use. ICTs are swiftly evolving technologies, and the most fluent ICT teachers need to continuously upgrade their skills and keep abreast of the latest developments and best practices. Teacher anxiety over being replaced by technology or losing their authority in the classroom as the learning process becomes more learner -centred- an acknowledged barrier to ICT adoption- can be alleviated only if teachers have a keen understanding and appreciation of their changing role.

\subsection{Education Administrators:}

Leadership plays a key role in ICT integration in education. Many teacher or student initiated ICT projects have been undermined by lack of support from the authority. For ICT integration programs to be effective and sustainable, administrators themselves must be competent in the use of technology, and they must have a broad understanding of the technical, curricular, administrative, financial, and social dimensions of ICT use in education.

\section{Technical Support Specialists}

They are essential to the continued viability of ICT use in a given school. The general competencies required are in the installation, operation and maintenance of technical equipment, network administration, and network security. Without on-site technical support, much time and money may be lost due to technical breakdowns. In the Philistines, for example, one of the major obstacles to optimizing computer use in high schools has been the lack of timely technical support. In some extreme cases involving schools in remote areas, disabled computers take months to be sent to the nearest city hundreds of kilometers away.

\section{Content Developers}

Content development is a critical area that is too often overlooked. The bulk of existing ICT-based educational material is likely to be in English or of little relevance to education in developing countries. There is a need to develop original 
educational content, adapt existing content, and convert print-based content to digital media. These are tasks for which content development specialists such as instructional designers, scriptwriters, audio and video production specialists, programmers, multimedia course authors, and web developers are needed.

\section{Language and Content}

English is the dominant language of the internet and estimated $80 \%$ of online content is in English. A large proportion of the educational software produced in the world market is in English. For developing countries in the Asia-pacific where English language proficiency is not high, especially outside metropolitan areas, this represents a serious barrier to maximizing the educational benefits of the World Wide Web.

\section{Advantages of Technology in Education}

There has been substantial evidence around the world that technology has become one of the most important and vital components to the success of a child's education. Some of the advantages that technology helps provide for children today are:

Student achievement: Technology has proven to help students achieve in reading, writing, and arithmetic. Each year teachers are instructed and challenged to meet Adequate Yearly Progress under the No Child left Behind Act of 2001. Technology gives educators one more tool to help them reach those goals. Students become engaged and can often times facilitate parent involvement at home.

Professional Requirements: Technology also benefits the educator because there are many opportunities for teachers to learn and acquire new skills over the internet, keep up with credentials and in return help them improve their teaching abilities.

Meeting special needs: Technology, more specifically with assistive technology special needs students, and student with disabilities have been able to achieve in areas and ways that would not have been possible. Technology creates individualized learning environments for students and really can play a major role in special need ones.

Continuing Education: Technology has made it possible for those who did not finish college or high school to get back into things without having to even leave the comfort of their own home. And technology has made it possible for continued education; those wanting to reach a little higher and gain more knowledge in something new or old. Technology brings the learning right to your students; wherever they may be.

Workforce skills: Technology has served students well because it has provided them with the skill and knowledge they need to enter the workforce. It is becoming increasingly difficult for teachers to reach every child in the classroom. Class sizes keep getting larger, but teachers remain still one of the lowest paid salary jobs in America. Yet the need is still there to reach and prepare them for the "real" world. And the real world today is a world full of technology. So if we do not provide technology in our education system then when will students have a chance to get familiar with it? How will they train themselves for the "real" world? Technology is therefore making it possible for teachers to reach more students, allowing students the time they need to succeed, and providing our future workforce with competent, knowledgeable employees.

\section{Conclusion}

A number of conclusions are arrived at with regard to the challenges facing the use of ICT in school management. At the policy level, the Ministry of Education had not come up with ICT policy, nor encouraged secondary schools to come up with the same in support of ICT use in school management, a shortcoming that for some time led to ad hoc acquisition of computers by the schools for lack of a proper strategy. Lack of permanent electricity supply from the mains in some of the schools with computers limited the use of ICT in school administration.

Computer purchases were not given priority in the annual school budgets and teachers and administrators were allocated time on the curriculum to use computers. At the same time, scarcity of computer hardware and software for school administrative purposes and access to computers were some of the greatest obstacles to the use of computers in the schools.. Further the study revealed that a high proportion of the teachers and administrators lacked training in essential ICT skills in database applications and administrative software needed for the effective application of ICT to school administration thus leading to limited use of computers for administrative purposes. Personal factors such as gender did appear to play a role in influencing the use of computers in school administration, with male teachers showing 
the highest tendency to use computers than their female counterparts.

On the extent of ICT use, the study showed that it was mainly for the facilitation of clerical activities and to a limited extent, other administrative duties, particularly processing of examinations. The power of ICT in timetabling, student records and other record keeping, financial management and decision making was minimal and yet to be tapped fully by the schools covered in the study. However, there was positive attitude towards the use of ICT and a realization by some of the staff that ICT could lead to enhancing administrative work performance, in particular contributing to more free time available for the teachers and administrators to do other worthwhile school duties.

From the challenges identified in the study of the use of ICT in school administration, a number of recommendations were made which in the first place involve the Government through the Ministry of Education and schools developing policies to guide the application of ICT in school management, including ensuring electricity is supplied to all secondary schools. Secondary, purchase of computers and administrative software should be budgeted for and acquired by the schools to avoid undue reliance on donated computers and software. Thirdly, training of teachers and administrators in application and administrative software programmes for school administration needs to be undertaken by the schools and universities training teachers. And lastly, schools ought to ensure that computers for administrative use are increased in number and are accessible to teachers and administrators, in particular the female teachers who need more encouragement and support from the school management to use computers.

Technology should not drive education; rather, educational goals and needs, and careful economics must drive technology use. Only in this way can educational institutions in developing countries effectively and equitably address the key needs of the population, to help the population as a whole respond to new challenges and opportunities created by an increasingly global economy. ICTs, therefore, cannot by themselves resolve educational problems in the developing world; as such problems are rooted in well entrenched issues of poverty, social inequality, and uneven development. What ICTs as educational tools can do, if they are used prudently, is enable developing countries to expand access to and raise the quality of education. Prudence requires careful consideration of the interacting issues that underpin ICT use in the school-policy and politics, infrastructure development, human capacity, language and content, culture, equity, cost and not least, curriculum and pedagogy.

\section{References}

Haveman, R.; Wolfe, B. (1995). "The Determinants Of Children's Attainments: A Review Of Methods and Findings". Journal of Economic Literature. Vol. 33, No. 4, Pp. 1829-1878. American Economic Association.

Hoxby, C. M. (2000). "The Effects of Class Size On Student Achievement: New Evidence FromPopulation Variation". Quarterly Journal Of Economics. No. 90, Pp. 1239-1285.

Jaag, C. (2006). "A Simple Model of Educational Production". Mpra Paper. No. 338. October.

Jaggia, S.; Kelly-Havke, A. (1999). "An Analysis Of The Factors That Influence Student Performance: A Fresh Approach to an Old Debate". Contemporary Economic Policy. Vol. 17, No. 2, Pp. 189-198.

Jepsen, C.; Rivkin, S. (2002). "What is the Trade-Off between Smaller Classes And Teacher Quality?". Nber Working Paper. No. 9205.

Kirkpatrick, H.; Cuban, H. (1998). "Computers Make Kids Smarter-Right?" Technos Quarterly.No. 7.

Krueger, A. B. (1999). "Experimental Estimates Of Educational Production Functions". Quarterly Journal of Economics. Vol. 114, No. 2, Pp. 497-532.

Kulik, J. A. (1994). "Meta-Analysis Study of Findings on Computer-Based Instruction". In: E.

L. Baker; H. F. O'neil. Technology Assessment in Education and Training. Hillsdale, Nj: Lawrence Erlbaum.

Lazear, E. P. (2001). "Educational Production". Quarterly Journal of Economics. Vol. 66, No. 3, Pp. 777-803.

Leuven, E.; Lindahl, M.; Oosterbeek, H.; Webbink, D. (2004). "The Effect of Extra Funding For Disadvantaged Pupils on Achievement". Iza Discussion Paper. No. 1122. Bonn: Institute For The Study of Labor.

Li, Y.; Le Boeuf, E. J.; Basu, P. K.; Turner, L. H. (2003). "Development Of A Web-Based Mass Transfer Processes Laboratory: System Development and Implementation". Computer Applications In Engineering Education. Vol. 11, No. 1, Pp. 67-74.

Lundin, J.; Magnusson, M. (2003). "Collaborative Learning in Mobile Work". Journal Of Computer Assisted Learning. No. 19, Pp. 273283.

Mosteller, F. (1995). "The Tennessee Study of Class Size in the Early School Grades". The Future of Children. Vol. 5, No. 2, Pp. 113127.

Murnane, R. J. (1975). The Impact of School Resources on the Learning of Inner City Children. Cambridge, Ma: Balinger Publishing Company.

Oecd (2006). Education Policy Analysis: Focus On Higher Education. Paris: Oecd.

Pozo, S.; Stull, C. A. (2006). "Requiring a Math Skills Unit: Results of A Randomized Experiment". American Economic Review. Vol. 96, No.2, Pp. 437-441

Raudenbush, S. W.; Willms, J. D. (1995). "The Estimation of School Effects". Journal Of Educational and Behavioral Statistics. Vol. 20, 
No. 4 (Winter), Pp. 307-336.

Reid, R. (1983). "A Note on The Environment As A Factor Affecting Student Performance In Principles of Economics". Journal of Economic Education. Vol. 14, No. 4, Pp. 18-22.

Rivkin, S. G.; Hanushek, E. A.; Kain, J. F. (2005). "Teachers, Schools and Academic Achievement". Econometrica. Vol. 73, No. 2, Pp. 417-458.

Rockoff, J. E. (2004). "The Impact of Individual Teachers on Student Achievement: Evidence From Panel Data". American Economic Review Papers and Proceedings. Vol. 94, №. 2, Pp.247-252.

Rosenshine, B. (1971). Teaching Behaviors and Student Achievement. London: National Foundation for Educational Research.

Sah, R. K.; Stiglitz, J. E. (1986). "The Architecture Of Economic Systems: Hierarchies And Polyarchies". American Economic Review. Vol 47, No. 2, Pp. 173-184.

Sharpe, A. (2004). "Ten Productivity Puzzles Facing Researchers". International Productivity Monitor. Vol 9, Pp. 15-24.

Sosin, K.; Blecha, B. J.; Agawal, R.; Bartlett, R. L.; Daniel, J. I. (2004). "Efficiency in the Use Of Technology in Economic Education: Some Preliminary Results". American Economic Review. May 2004 (Papers and Proceedings), Pp. 253-258.

Todd, P. E.; Wolpin, K. I. (2003). "On The Specification and Estimation Of The Production Function For Cognitive Achievement". The Economic Journal. Vol.113, No. 485, Pp. F3-F33.

Unesco (2003). Manual for Pilot Testing the Use of Indicators to Assess Impact of ICT Use In Education [Online]. $<$ Http://Www.Unescobkk.Org/Education/lct/Resource>

Wilson, W. J. (1987). The Truly Disadvantaged. Chicago: The University Of Chicago Press. 
